\title{
Commentary \\ Long-term outcome after intensive care: can we protect the kidney?
}

Max Bell and Claes-Roland Martling

Department of Anaesthesiology and Intensive Care Medicine, Karolinska University Hospital, Solna, Sweden

Corresponding author: Max Bell, max.bell@karolinska.se

Published: 19 July 2007

This article is online at http://ccforum.com/content/11/4/147

(c) 2007 BioMed Central Ltd
Critical Care 2007, 11:147 (doi:10.1186/cc5959)

17.4\%). The reasons for initiating renal replacement therapy also differed; for instance, sepsis was more common in the CRRT group. Considering the different patient categories, the authors unsurprisingly found that unadjusted hospital survival was lower in the CRRT group. Multivariable logistic regression, however, showed that the choice of renal replacement therapy was not an independent predictor of hospital survival or of dialysis-free hospital survival. Most importantly, the study showed that the choice of CRRT was a predictor of dialysis independence at hospital discharge among survivors (odds ratio $=3.3,95 \%$ confidence interval $=$ 1.8-6.0, $P<0.0001)$. The authors conclude that, worldwide, the choice of CRRT as the initial therapy is not a predictor of hospital survival or of dialysis-free hospital survival, but that it is an independent predictor of renal recovery among survivors. The authors speculate on the reasons for this, and on whether hypotension plays a part. The numbers of reported hypotensive episodes were indeed significantly higher in the IRRT group than in the CRRT group (27.9\% and $18.8 \%$, respectively).

Perhaps it is the poor outcome [2] - measured as mortality of critically ill patients with acute renal failure that has prevented the research community from evaluating the determinants of long-term morbidity. The vast differences between countries and regions concerning the choice of the initial technique of renal replacement therapy could also have hampered this field of research [3-5]. Surgery and internal medicine are disciplines with several hundred years of history - is this an explanation for the fact that long-term outcome is an integrated and natural part of clinical studies in those fields?

The adolescent specialty of intensive care medicine, born in 1952 after the polio epidemic in Copenhagen [6], has been satisfied with less; namely, with the reporting of short-term mortality. 
Renal recovery is an important measure of outcome for many reasons. First, chronic dialysis therapy is associated with significant impairment of health-related quality of life [7-9]. Dialysis therapy is also costly, with annual costs in the range of $\$ 51,252-69,517[10,11]$. One study showed that the estimated cost per quality-adjusted life-year saved by initiating dialysis was $\$ 128,200$ [12]. Finally, the overall mortality of patients with renal failure requiring dialysis exceeds that of the general population. Recent Swedish data from the Swedish Register of Active Uremia report a $28.1 \%$ yearly mortality ratio for patients on chronic hemodialysis [13].

In collaboration with the Swedish Intensive Care Nephrology Group, we performed a study of 2,202 patients with acute renal failure [14]. These patients were treated with either CRRT or IRRT in 32 Swedish intensive care units. The duration of follow-up ranged from 3 months to 10 years.

We addressed the same issue as the Beginning and Ending Supportive Therapy investigators [1]; namely whether treatment modality used during intensive care affects renal recovery. A total of 1,100 patients died within 90 days of initial dialysis. No association was found between dialysis modality and 90day mortality. Among the 90-day survivors, 944 had received CRRT and 158 had received IRRT. The risk of end-stage renal disease requiring hemodialysis was considerably higher in 90-day survivors treated with IRRT than in those treated with CRRT (adjusted odds ratio $=2.60,95 \%$ confidence interval $=1.5-4.3$ ). The trend towards a higher risk of endstage renal disease with IRRT, however, decreased with increasing duration of follow-up. Among the 90-day survivors who did develop end-stage renal disease, the risk of death was markedly higher in patients treated with IRRT than in those treated with CRRT (hazard ratio $=2.3,95 \%$ confidence interval $=1.3-4.1$ ).

In conclusion, the Beginning and Ending Supportive Therapy study shows that CRRT and IRRT are used for quite different patient categories, where sicker and more hemodynamically unstable patients more often than not are treated with CRRT. Furthermore, both that study and the national study by the Swedish Intensive Care Nephrology Group investigators point to the fact that CRRT is associated with a bigger chance of renal recovery.

The findings of these two large studies $(1,218$ and 2,202 patients, respectively) are in keeping with previous clinical evidence. In a randomized controlled trial by Mehta and colleagues, benefits for CRRT regarding renal recovery were seen [15]. Chronic renal insufficiency at death or at hospital discharge was diagnosed in $17 \%$ of patients with initial therapy of IRRT versus only $4 \%$ of patients whose initial therapy was CRRT $(P=0.01)$. For patients receiving an adequate trial of monotherapy, the recovery of renal function was $92 \%$ for CRRT versus $59 \%$ for IRRT $(P<0.01)$. Finally, a higher percentage of subjects crossing over from IRRT to
CRRT recovered their renal function compared with the patients crossing over in the opposite direction (45\% versus $7 \%$, respectively; $P<0.01$ ) [15]. As higher costs associated with CRRT have been used in the debate regarding the choice of modality, the downstream costs of end-stage renal disease requiring chronic hemodialysis may have to be considered in future discussions. Naturally, we do look forward to long-term studies of renal outcome on patients treated with sustained low efficiency (daily) dialysis.

As members of the intensive care research community, we need to strive towards gathering more data concerning longterm outcome. The studies mentioned above are welcome additions to critical care epidemiology in general, and to the field of acute kidney injury in particular.

\section{Competing interests}

The authors declare that they have no competing interests.

\section{References}

1. Uchino S, Bellomo R, Kellum JA, Morimatsu H, Morgera S, Schetz MR, Tan I, Bouman C, Macedo E, Gibney N, et al.: Patient and kidney survival by dialysis modality in critically ill patients with acute kidney injury. Int J Artif Organs 2007, 30:281-292.

2. Uchino S, Kellum JA, Bellomo R, Doig GS, Morimatsu H, Morgera $\mathrm{S}$, Schetz M, Tan I, Bouman C, Macedo E, et al:: Acute renal failure in critically ill patients: a multinational, multicenter study. JAMA 2005, 294:813-818.

3. Mehta RL, Letteri JM: Current status of renal replacement therapy for acute renal failure. A survey of US nephrologists. The National Kidney Foundation Council on Dialysis. Am J Nephrol 1999, 19:377-382

4. Silvester W, Bellomo R, Cole L: Epidemiology, management, and outcome of severe acute renal failure of critical illness in Australia. Crit Care Med 2001, 29:1910-1915.

5. Venkataraman R, Kellum JA, Palevsky P: Dosing patterns for continuous renal replacement therapy at a large academic medical center in the United States. J Crit Care 2002, 17:246250.

6. Wackers GL: Modern anaesthesiological principles for bulbar polio: manual IPPR in the 1952 polio-epidemic in Copenhagen. Acta Anaesthesio/ Scand 1994, 38:420-431.

7. Gokal R: Quality of life in patients undergoing renal replacement therapy. Kidney Int Supp/ 1993, 40:S23-S27.

8. de Wit GA, Ramsteijn PG, de Charro FT: Economic evaluation of end stage renal disease treatment. Health Policy 1998, 44: 215-232.

9. Churchill DN, Torrance GW, Taylor DW, Barnes CC, Ludwin D Shimizu A, Smith EK: Measurement of quality of life in endstage renal disease: the time trade-off approach. Clin Invest Med 1987, 10:14-20.

10. Manns BJ, Taub KJ, Donaldson C: Economic evaluation and end-stage renal disease: from basics to bedside. Am J Kidney Dis 2000, 36:12-28.

11. Lee H, Manns B, Taub K, Ghali WA, Dean S, Johnson D, Donaldson $C$ : Cost analysis of ongoing care of patients with endstage renal disease: the impact of dialysis modality and dialysis access. Am J Kidney Dis 2002, 40:611-622.

12. Hamel MB, Phillips RS, Davis RB, Desbiens N, Connors AF, Jr, Teno JM, Wenger N, Lynn J, Wu AW, Fulkerson W, Tsevat J: Outcomes and cost-effectiveness of initiating dialysis and continuing aggressive care in seriously ill hospitalized adults. SUPPORT Investigators. Study to Understand Prognoses and Preferences for Outcomes and Risks of Treatments. Ann Intern Med 1997, 127:195-202.

13. Schon S, Ekberg H, Wikstrom B, Oden A, Ahlmen J: Renal replacement therapy in Sweden. Scand J Urol Nephrol 2004, 38:332-339.

14. Bell M, Granath F, Schon S, Ekbom A, Martling CR: Continuous renal replacement therapy is associated with less chronic 
renal failure than intermittent haemodialysis after acute renal failure. Intensive Care Med 2007, 33:773-780.

15. Mehta RL, McDonald B, Gabbai FB, Pahl M, Pascual MT, Farkas A, Kaplan RM: A randomized clinical trial of continuous versus intermittent dialysis for acute renal failure. Kidney Int 2001, 60:1154-1163. 